\title{
Guidelines for Visual-Sensitive EEG Testing
}

\author{
Prepared by a Task Force* of the Canadian Society of Clinical \\ Neurophysiologists
}

Can. J. Neurol. Sci. 2008; 35: 133-135

\begin{abstract}
Adrian \& Matthews were likely the first to demonstrate the photic driving response in man. ${ }^{1}$ Intermittent photic stimulation (IPS) became an integral part of the electroencephalogram (EEG) after the seminal contributions of Walter et $\mathrm{al}^{2}$ and Gastaut et al. ${ }^{3}$ Because of the considerable variability in the equipment and methods used for IPS, experts in Europe developed a consensus for standardizing techniques. ${ }^{4-6}$ However, The American EEG Society, ${ }^{7}$ the International Federation of Clinical Neurophysiology, ${ }^{8}$ the Canadian Society for Clinical Neurophysiologists (CSCN) ${ }^{9}$ and The American Clinical Neurophysiology Society ${ }^{10}$ have only made passing reference to IPS. The European recommendations for IPS ${ }^{4-6}$ provide an excellent framework for adoption. The method is demonstrated with video in Zifkin and Kasteleijn-Nolste Trenité ${ }^{11}$ With a few minor additions, the guidelines for IPS in this document are identical. In addition, pattern-sensitivity and video games have also been addressed. In this paper, testing for visualsensitivity encompasses IPS, testing for pattern -sensitivity and assessment for video game induced seizures.
\end{abstract}

\section{Intermittent Photic Stimulation (IPS)}

\section{Photic Stimulator}

The Grass (model PS22) is the gold standard because it has been used in several studies and meets the desired standards, ${ }^{4-6}$ although other manufacturers supply similar devices. The European group recommended the following specifications for photic stimulators: ${ }^{4-6}$ (i) Maximal intensity $\geq 100$ Nit-s per flash, (ii) circular field of diameter $13 \mathrm{cms}$, (iii) Xenon discharge lamp, (iv) granular diffuser and lamp housing/reflector resulting in a spatial distribution of luminous intensity similar to that of the Grass photic stimulator, (v) No pattern or grid on the stimulator but provision for inserting patterns in front of the diffuser as required and (vi) should deliver single flashes and trains of flashes of constant intensity at frequencies between 1 and $60 \mathrm{~Hz}$, (vii) Intensity of 1 joule per flash and luminance of 100 nit-s per flash. As (the flash) stimulator ages, the intensity may change. The granular diffuser reduces the differences related to different flash tubes and stimulator surfaces. Digital EEG systems now usually come with LED-based stimulators. Although LED-based stimulators may not exhibit aging effect, we are uncertain if these stimulators meet the criteria that have been set. Thus, the Schwartzer lamp is a line of several LEDs in a rectangular housing. The spatial distribution of the flashes may not be the same as with a round lamp with diffuser. Hence, laboratories should check and note the type, intensity and luminance levels of their photic stimulators. Studies assessing the reliability of LEDbased stimulators by comparing them against an accepted 'gold standard' are needed. Manufacturers should be encouraged to standardize photic stimulators and use uniform terminology to express luminance.

\section{Montage}

We are not aware of any published studies that support the use of a specific montage for photic stimulation. A minimum of 16 channels should be used. The montage should display activity from all head regions. Digital machines permit reformatting. Hence, the choice of montage: bipolar or referential is not crucial. The conventional bipolar double anteroposterior chain is satisfactory. The montage must include frontopolar and occipital coverage. We suggest that a combination of a referential and bipolar montage be used. Since photic responses can be focal (ex. occipital or temporal) or generalized this combination would capture both. One example: Fp1-F3, F3-C3, C3-P3, P3-O1, Fp2-F4, F4-C4, C4-P4, P4-O2, Fp1-A1, F3-A1, O1-A1, T5-A1, Fp2A2, F4-A2, O2-A2, T6-A2. The ipsilateral ear montage may not be appropriate in the presence of mid or posterior temporal abnormalities in the resting record, and a $\mathrm{Cz}$ reference could be employed. In addition, a posterior bipolar 'hatband' montage across the occipital regions may better display some responses. The ability to reformat the EEG permits the electroencephalographer to tailor the montage to the clinical situation. As in the resting record, it is often useful to monitor eye movements to help distinguish between artifact and brain activity.

\section{Procedure}

i) IPS, which refers to intermittent stimulation using a photic stimulator, should not be performed within three minutes of hyperventilation (HV) to ensure that late effects of $\mathrm{HV}$ do not confound findings.

\footnotetext{
*Task Force Members: S.S. Seshia, G.B. Young, B.G. Zifkin. Received September 10, 2007. Final Revisions Submitted November 16, 2007. Reprint requests to: Canadian Society of Clinical Neurophysiologists, 709-7015 MacLeod Trail SW, Calgary, Alberta, T2H 2K6, Canada.
} 
ii) The nasion to lamp distance should be $30 \mathrm{~cm}$, a distance used in several trials; this viewing distance provides a large enough visual field with the $13 \mathrm{~cm}$ Grass lamp housing and is also appropriate for visual accommodation in 'young' patients. The technologist can also observe the patient without difficulty.

iii) The subject can be lying down or sitting. The patient/caregiver/technologist should activate an event marker if subjective or objective events occur.

iv) Ideally, subjects should be awake during photic stimulation. Individuals seem to be less photic-sensitive when sleeping. Infants often sleep during the EEG and are usually upset during IPS. In them, photic stimulation can be done asleep but may have to be repeated awake at a separate sitting if the information (that may be obtained from such stimulation) is considered important for clinical management.

iv) The ambient light should be dim 'just sufficient to observe the patient.'Ambient light can influence results of IPS. Hence, laboratories should 'standardize' the ambient lighting in the room to enhance consistency and minimize inter test/tester variability.

v) Flashes should be delivered in separate trains of ten seconds for each frequency at minimum intervals of seven seconds (likely to minimize the risk of clinical seizures). The eyes should be open and directed at the centre of the lamp for the first five seconds and then closed for the next five seconds. Photic stimulation should continue throughout the tensecond period, ensuring testing during eye-closure. The period of five seconds is sufficient to elicit a photoparoxysmal response (PPR). ${ }^{5}$ Jeavons \& Harding ${ }^{12}$ and Harding \& Jeavons ${ }^{13}$ found that most patients (88\%) were more sensitive (spike-wave or polyspike wave PPR) with eyes open than eyes closed, a few (7\%) were more sensitive when the eyes were closed rather than open and the abnormal PPR occurred only during eye closure in $3 \%$, emphasizing the importance of testing under all three conditions. The following frequencies are used in sequence: $1,2,3,4,6,8,10,12,14,16,18,20$ then $60,50,40,30,25$ and 20. The selection of frequencies is based on the data of Jeavons and Harding ${ }^{12}$ and Harding and Jeavons. ${ }^{13}$ Stimulation should be stopped if any generalized epileptiform activity is observed. It is essential that $50 \mathrm{~Hz}$ and $60 \mathrm{~Hz}$ be included in the testing because the information may help to predict the sensitivity to television. ${ }^{14}$ Topalkara et al found that frequency specific habituation of the PPR can occur if IPS is repeated immediately ('consecutively'). ${ }^{15}$ They suggest that attempts to confirm sensitivity to a particular frequency (if clinically important) should be separated in time, ideally at a separate session.

vi) The technologist should assess objectively for absence and myoclonic seizures during any PPR. It may be necessary to place surface EMG electrodes to detect myoclonus.

(vii) IPS should be performed fully or not at all. Reasons for not performing IPS or for discontinuing it prematurely should be documented.

\section{Situations in which IPS should always be done}

A. Asymmetry of alpha rhythm or abnormalities of the background over the posterior regions in the base-line record.
In these situations a significant asymmetry of the photic driving response $(>50 \%)$ would add further support to dysfunction over the posterior region/s.

B. Children with neurodevelopmental regression. A relatively prominent response at low rates of stimulation has been found in ceroid lipofuscinosis. Adults with 'neuro-degenerative' diseases may also exhibit such a response.

C. All those referred with (possible) seizures/epilepsy, especially those in the pediatric age group (i.e. to 20 years-of-age), except neonates (unless the history is of myoclonic seizures).

\section{Situations in which IPS need not be done}

IPS need not be done if epilepsy /neuro-cognitive (developmental) decline are not clinical features.

\section{Situations in which IPS should not be done}

IPS should not be done when the patient is in clinical status epilepticus.

\section{Special circumstances}

1. Neonates. The role of IPS in neonates has not been studied. We suggest that IPS be done in neonates who have myoclonic seizures.

2. The elderly. The role of IPS in the elderly and very elderly has not been studied. We suggest that IPS be done if the clinical problems include seizures or neuro-cognitive decline.

3. Pregnancy. All women of childbearing age should be asked if they are pregnant. We are not aware of any data that would contraindicate IPS during pregnancy other than the risk of provoking a seizure. Since the findings on IPS may help with syndromic diagnosis, IPS may be performed if the patient's neurologist or obstetrician has sanctioned it. When in doubt, the technologist may omit IPS but this omission should be included in the report.

4. We believe that IPS can be done even if there is considerable inter-ictal epileptiform activity on the EEG and in those who may exhibit electrographic status epilepticus (without clinical seizures) as the findings may contribute to diagnosis and management. In these situations, it would be prudent for the technologist to discuss the case with the electroencephalographer before performing IPS.

\section{TESTING FOR PATTERN-SENSITIVITY}

If the subject is suspected to have seizures triggered by patterns then pattern sensitivity should be tested. Subjects with pattern-sensitive epilepsy may not be sensitive to IPS. In order to maximize patient co-operation, testing for patternsensitivity should be done during a recording dedicated for this purpose.

\section{(i) The Mayo Clinic method ${ }^{16}$}

Patients are asked to scan a pattern of parallel black lines (Mayo Clinic pattern 44) on an $8.5 \times 11.5$ inch $(22 \times 29 \mathrm{~cm})$ laminated card for $10 \mathrm{~s}$ at a distance in clear focus for reading. The room should be fully illuminated and illumination should be standardized for all such recordings in the laboratory to minimize inter-test variability. The patient should be seated. In the event of a PPR, testing should be done with other 
patterns (described) for ten seconds alternating with a white card. Once the patterns are presented in a stationary position, they are presented again with each pattern shaken horizontally and vertically for ten seconds.

\section{(ii) Darby et all}

The pattern is circular, diameter $48 \mathrm{~cm}$, with a central fixation point, viewed at a distance of $57 \mathrm{~cm}$. The pattern consists of parallel black and white stripes, each $2.5 \mathrm{cms}$ wide. The pattern should be well illuminated so that the average luminance is at least $200 \mathrm{~cd} / \mathrm{m}^{2}$. The patient should stare at the fixation point in the centre of the pattern. The pattern is held steady for 30 seconds and then oscillated orthogonal to the line orientation if no EEG abnormality has been evoked. The optimal frequency of oscillation is about $20 \mathrm{~Hz}$ attainable with a special device.

\section{TESTING FOR VIDEO GAME PROVOKED SEIZURES}

The characteristics of the video game are important determinants of seizure provocation. For this reason, when a patient has a seizure whilst playing a video game, we suggest that the provoking effects of the same game be tested during the EEG.

\section{GENERAL POINTS}

1. Clinical information provided (even by neurologists) on request forms is often inadequate. Although technologists take excellent histories prior to the recording, the information they obtain may not enable them to make a clinical diagnosis and determine if IPS should be done or not. We believe that the suggestions provided will cover most eventualities.

2. To remind the referring physician to indicate whether or not IPS/visual stimulation should be done or not, we suggest that the EEG requisition contain that option, e.g., visual (photic) stimulation OK? _ Yes/_No.

3. The occurrence of a PPR. Even if the information on the request form is scarce, the electroencephalographer (in his/her report) may use his/her discretion and list some of the epilepsy syndromes in which PPR occur (this may avoid the prescription of an inappropriate anti-convulsant).

4. We have not discussed the classification or significance of the various responses (including PPR) to visual stimulation.

Visual-sensitive epilepsies have been reviewed recently. ${ }^{18-21}$

\section{SUMMARY}

A high level of evidence does not exist for many aspects of testing for visual sensitivity. Evidenced-based studies are needed in several areas, including (i) reliability of LED-based stimulators, (ii) the most appropriate montages for displaying responses, (iii) testing during pregnancy, and (iv) the role of visual-sensitivity testing in the diagnosis of neurological disorders affecting the elderly and very elderly. Standardization of testing across the country will be an important step in filling the existing gaps of knowledge.

\section{ACKNOWLEDGEMENTS}

We are grateful to Professor C. Binnie, Dr. D.W. Klass, Ms. P.R. Roth EEG T, Dr. N. So, and Dr. B.Westmoreland for responding to our request for information. We thank those who provided suggestions for improvement. Ms. Karen Bryan and Ms. Susan Rahey of CAET provided important practical suggestions.

\section{REFERENCES}

1. Adrian ED, Matthews BHC. The Berger Rhythm: Potential changes from the occipital lobes in man. Brain. 1934; 57:355-85.

2. Walter WG, Dovey VJ, Shipton H. Analysis of the electrical response of the human cortex to photic stimulation. Nature. $1946 ; 158: 540-1$

3. Gastaut H, Roger Y, Gastaut Y. Les formulas expérimentales de l'épilepsie humaine: l'épilepsie induite par la stimulation lumineuse intermittente rythmée ou épilepsie photogénique. Rev Neurol. 1948; 80:161-83.

4. Trenité DG, Binnie CD, Harding GF, Wilkins A, Covanis T, EegOlofsson $\mathrm{O}$, et al. Medical technology assessment. Photic stimulation-standardization of screening methods. Neurophysiol Clin. 1999a; 29:318-24.

5. Kasteleijn-Nolst Trenité DGA, Binnie CD, Harding GFA, Wilkins A. Photic stimulation: standardization of screening methods. Epilepsia. 1999b; 40 suppl 4: 75-9.

6. Rubboli G, Parra J, Seri S, Takahashi T, Thomas P. EEG diagnostic procedures and special investigations in the assessment of photosensitivity. Epilepsia. 2004; 45 suppl 1: 35-9.

7. American electroencephalographic society. Guidelines in electroencephalography, evoked potentials and polysom-nography. J Clin Neurophysiol. 1994; 11:2-9.

8. Nuwer MR, Comi G, Emerson R, Fuglsang-Frederiksen A, Guérit JM, Hinrichs $\mathrm{H}$, et al. IFCN standards for digital recording of clinical EEG. In: Deuschl G, Eisen A, Editors. Recommendations for the practice of clinical neurophysiology. 2nd revised and enlarged edition. Electroenceph Clin Neurophysiol. 1999; suppl 52:11-4.

9. Task Force of the Canadian Society of Clinical Neurophysiologists. Minimal standards for electro-encephalography in Canada. Can J Neurol Sci. 2002; 29:216-20.

10. American Clinical Neurophysiological Society. ACNS 2006 Guidelines. J Clin Neurophysiol. 2006; 23:85-183.

11. Zifkin BG, Kasteleijn-Nolst Trenité D. Reflex epilepsy and reflex seizures of the visual system: a clinical review. Epileptic Disord. 2000; 2:129-36.

12. Jeavons PM, Harding GFA. Photosensitive epilepsy. Clinics in developmental medicine no. 56. London: Spastics International Medical Publications; 1975.

13. Harding GFA, Jeavons PM. Photosensitive epilepsy. Clinics in Developmental Medicine no.133, London, UK: Mackeith Press; 1994.

14. Wilkins AJ, Darby CE, Binnie CD, Stefansson SB, Jeavons PM, Harding GF. Television epilepsy: the role of pattern. Electroencephalogr Clin Neurophysiol. 1979; 47:163-71.

15. Topalkara K, Alarcon G, Binnie CD. Effects of flash frequency and repetition of intermittent photic stimulation on photoparoxysmal responses. Seizure. 1998; 7:249-55.

16. Radhakrishnan K, St Louis EK, Johnson JA, McClelland RL, Westmoreland BF, Klass DW. Pattern-sensitive epilepsy: electroclinical characteristics, natural history, and delineation of the epileptic syndrome. Epilepsia. 2005; 46:48-58.

17. Darby CE, Wilkins AJ, Binne CD, De Korte RA. Routine testing for pattern sensitivity. J Electrophysiol Technol. 1980; 6:202-10.

18. Zifkin BG, Andermann F. Visual-sensitive epilepsies. ILAE Web site 2005. http://www.ilae-epilepsy.org/visitors/centre/ctf/ index.cfm. Last accessed July 17, 2007.

19. Seshia SS, Carmant L. Visual-sensitive epilepsies: classification and review. Can J Neurol Sci. 2005; 32: 298-305.

20. Harding G, Wilkins AJ, Erba G, Barkley GL, Fisher RS. Epilepsy Foundation of America Working Group. Photic- and patterninduced seizures: expert consensus of the Epilepsy Foundation of America Working Group. Epilepsia. 2005; 46: 1423-5.

21. Fisher RS, Harding G, Erba G, Barkley GL, Wilkins A. Epilepsy Foundation of America Working Group. Photic- and patterninduced seizures: a review for the Epilepsy Foundation of America Working Group. Epilepsia. 2005; 46: 1426-41. 